Supplement of Atmos. Chem. Phys., 19, 2765-2785, 2019

https://doi.org/10.5194/acp-19-2765-2019-supplement

(C) Author(s) 2019. This work is distributed under

the Creative Commons Attribution 4.0 License.

(c) (1)

\section{Atmospheric \\ Chemistry \\ and Physics}

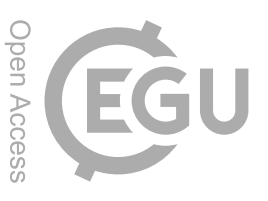

Supplement of

\title{
Towards a satellite formaldehyde - in situ hybrid estimate for organic aerosol abundance
}

\section{Jin Liao et al.}

Correspondence to: Jin Liao (jin.liao@nasa.gov)

The copyright of individual parts of the supplement might differ from the CC BY 4.0 License. 
Supplementary information:
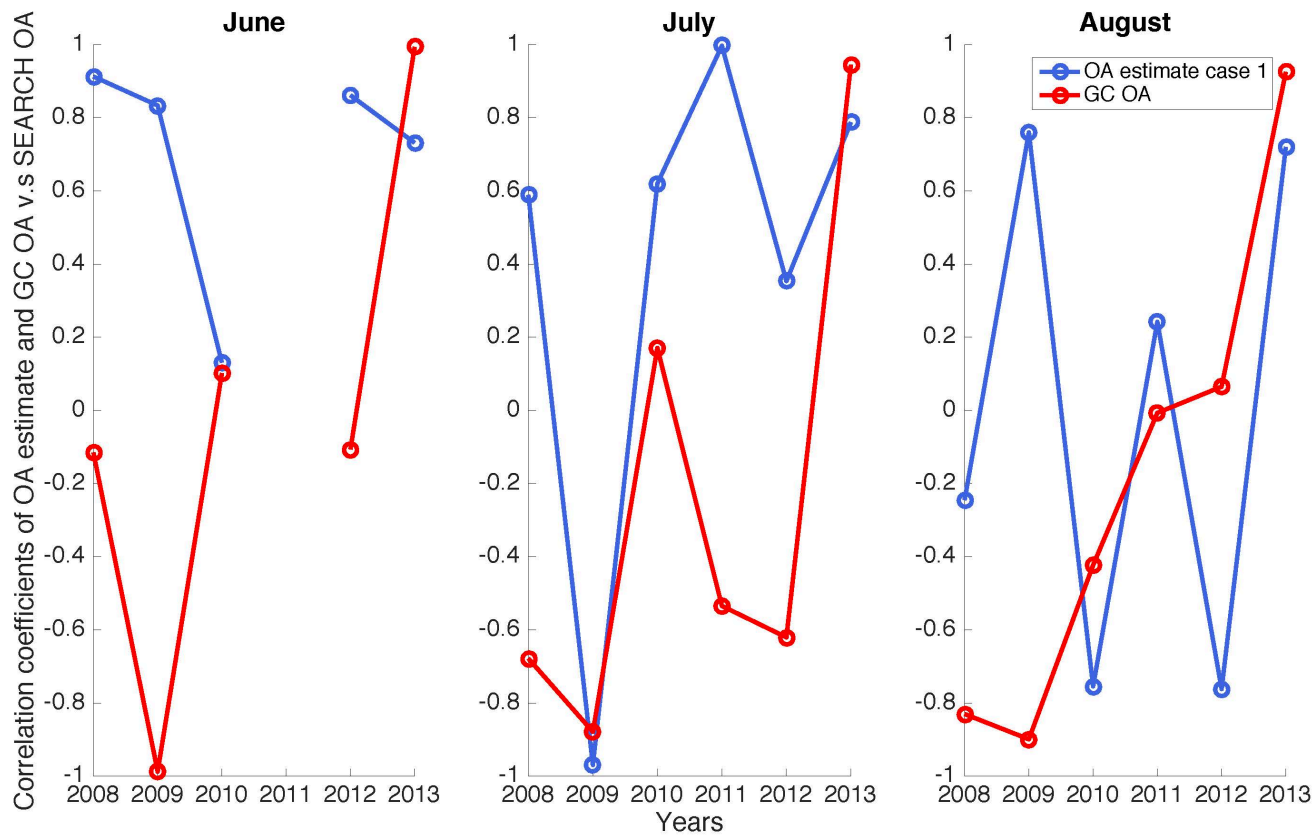

Figure S1. The correlation coefficients of the linear regression between OA estimate case 1 (blue) and GEOS-Chem OA (red) vs. SEARCH OA for June, July and August 20082013.
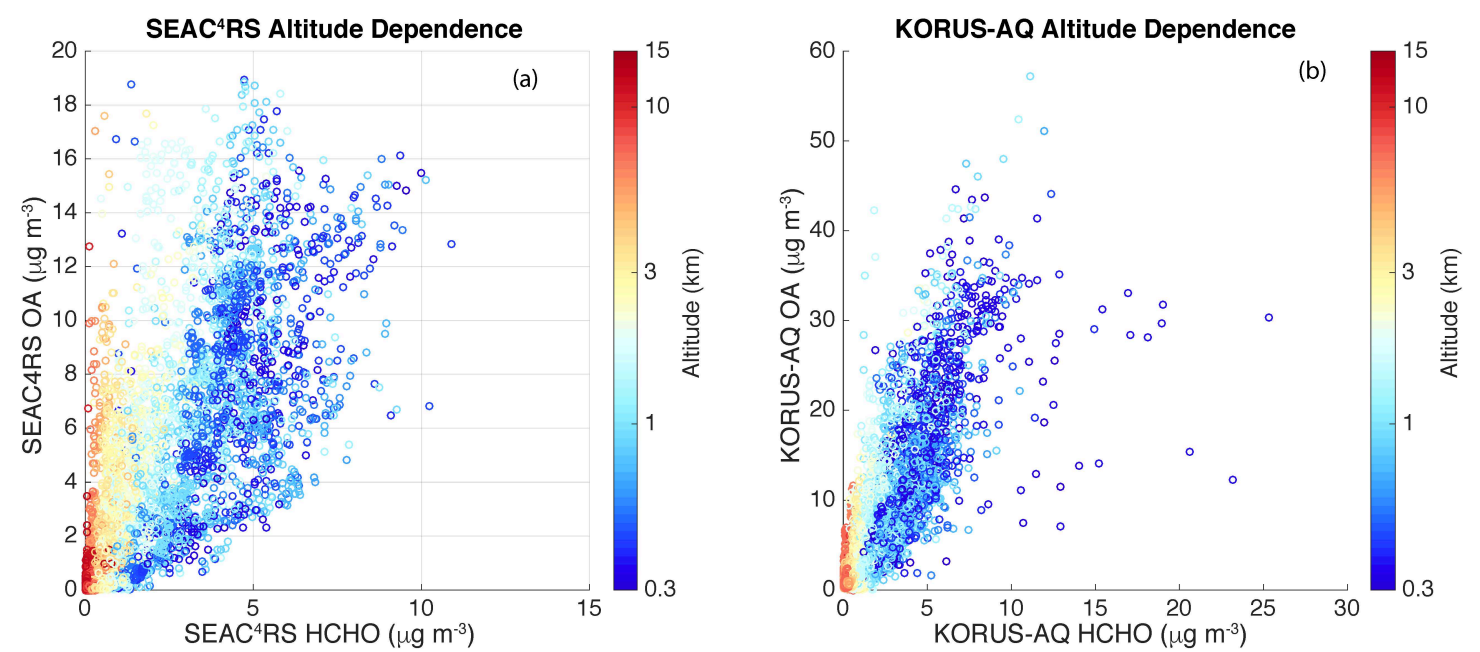

Figure S2 (a) A scatter plot of OA vs. HCHO for SEAC ${ }^{4} \mathrm{RS}$ non-biomass burning data colored by altitude. (b) A scatter plot of OA vs. HCHO for KORUS-AQ data colored by altitude. 

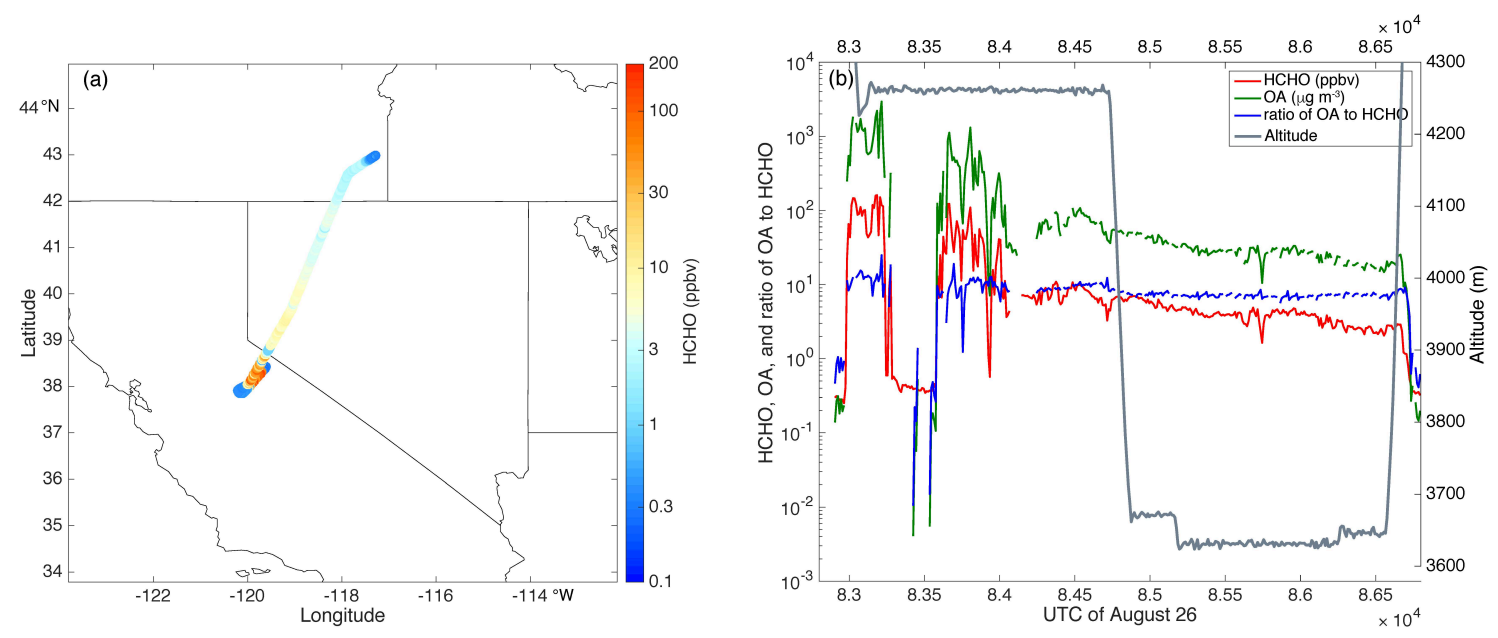

Figure S3

(a) SEAC ${ }^{4}$ RS flight track that sampled the Rim Fire plume on August 26, 2013, colorcoded with HCHO mixing ratios measured by ISAF. The sampling flight track was parallel to wind direction with an average wind speed of $4 \mathrm{~ms}^{-1}$. The plume transport time from the source to the furthest sampling location shown was about 20 hours from wind speeds and distance (b) The time series plot of $\mathrm{HCHO}$ (red), OA (green), the ratio of OA to $\mathrm{HCHO}$ (blue), and altitude (gray) of the plume sampled by the flight track. 